\title{
Effect of Diphosphate on Proliferation of Osteoblasts in Mice
}

\author{
WENXIONG HU, J. JIANG, AND HUA LI*
}

Department of Orthopaedics, Hainan West Central Hospital, Danzhou City, Hainan Province-571700, China

\begin{abstract}
Hu et al.: Rehabilitation of patients with coronary heart disease after percutaneous coronary intervention
In order to investigate the effect of diphosphate on the proliferation and differentiation of mouse osteoblasts and to further explore the optimal concentration of diphosphate, mouse embryo osteoblasts precursor cells are used as the research object. The expression level of its messenger ribonucleic acid is detected by real-time quantitative polymerase chain reaction (real-time polymerase chain reaction). $3-(4,5)$ - dimethylahiazo (-z-yl) -3, 5-di-phenytetrazolium bromide method is used to detect the proliferation of mouse embryo osteoblasts precursor cells and its effect on alkaline phosphatase activity, so as to explore its correlation. The results show that mouse embryo osteoblasts precursor cells have the greatest value-added effect, the most significant gene expression and the highest alkaline phosphatase activity at the concentration of 10-8 $M$ diphosphate. The results are as expected. More accurate, standardized and quantifiable data for mouse embryo osteoblasts precursor cell proliferation are obtained through experiments. There are still some shortcomings in the research process, but the results of this study still provide some guidance for exploring more precise mechanism of action in the future. Therefore, the results of this study provide guidance for exploring more precise mechanisms in the future, which is the value of this study.
\end{abstract}

Key words: Diphosphate, alkaline phosphatase, 3- $(4,5)$ - dimethylahiazo (-z-yl) -3, 5-di-phenytetrazolium bromide method (MTT), real-time quantitative polymerase chain reaction

Diphosphate is a synthetic, metabolically stable inorganic pyrophosphate analogue. It is formed by replacing the P-O-P bond in pyrophosphate with the non-hydrolyzed P-C-P bond ${ }^{[1]}$. The molecular configurations of P-O-P and P-C-P determine that the three-dimensional structure of P-O-P and P-C-P can bind to $\mathrm{Ca}^{2+}$ and other divalent ions, which is the basis of the targeting properties of bone diphosphate. At present, diphosphate has been developed to the third generation, which is widely used in the treatment of bone resorption-increasing diseases (such as osteoporosis, oncogenic osteopathy, Paget disease, hypercalcemia, etc.), especially in the treatment of osteoporosis and bone tumors ${ }^{[2]}$. Diphosphates are generally divided into two categories: nitrogen-containing diphosphates and non-nitrogen-containing diphosphates. Nitrogencontaining diphosphates can inhibit the methylvalerate pathway of cholesterol synthesis by selectively inhibiting the binding of isoprene pyrophosphate to farnesyl chlorosynthase, resulting in a decrease in the number of farnesyl pyrophosphate vinegar. This reduction ultimately leads to the lack of isoprenylation of guanosine triphosphate (GTPase), which is essential for osteoclasts to function and survive, and cell death ${ }^{[3,4]}$. Non-nitrogenous diphosphates incorporate an inactive adenosine triphosphate (ATP) analogue into cells, which has no energy reserve to release and thus leads to cell death. The mechanism of action of diphosphate is only specific to osteoclasts, and more and more studies have shown that diphosphate also plays a role in osteoblasts ${ }^{[5]}$. For example, Giuliani et al. reported that diphosphate and itophosphoric acid enhanced the expression of Interleukin (IL)-6 in osteoblasts. Shanbhag et al. found that apart from inhibiting the osteolysis caused by wear debris, diphosphate also increased themineralizedbonemass in theimplantholeby $115 \%{ }^{[6,7]}$. Plotkin et al. reported that diphosphate could inhibit the apoptosis of human osteoblasts, and mouse osteoblasts $^{[8,9]}$. Pan et al. confirmed that Milephosphate decreased the expression of transmembrane Receptor activator of nuclear factor kappa-B ligand (RANKL) in osteoblasts by increasing the activity of tumor necrosis factor- $\alpha$ (TNF- $\alpha$ ) invertase. Based on these results, it is speculated that diphosphate has a direct

*Address for correspondence

E-mail: huwenxiong_hwx2010@163.com

Special Issue 8, 2020 
synthesizing effect on osteoblasts ${ }^{[10]}$. Although there are many studies on the effects of diphosphate on the proliferation and differentiation of mouse osteoblasts, there are few studies on the optimal concentration of diphosphate. Therefore, in this study, mouse embryo osteoblasts precursor cells (MC3T3-E1) are taken as the research object and the precise quantitative study of DPI concentration on mouse osteocyte proliferation is further explored, so as to provide new ideas for future research.

\section{MATERIALS AND METHODS:}

\section{Objects, instruments and reagents:}

Mouse MC3T3-E1 cells, $40^{\circ}$ refrigerator, $20^{\circ}$ refrigerator, $\mathrm{CO}_{2}$ incubator, ordinary optical microscope, and microscope digital camera system (DP 11) are needed. Bio-red 450 enzyme-linked immunosorbent assay (ELISA), H- Dulbecco's Modified Eagle Medium (H-DMEM) medium (Hangzhou Gino Medical Technology Co., Ltd.), and trypsin (Hangzhou Gino Medical Technology Co., Ltd.) are also needed. Fetal bovine serum, Allen phosphoric acid MERCK, $\beta$-glycerol-phosphate Sigma, dexamethasone Sigma, L-ascorbic acid Sigma, 5-di-phenytetrazolium bromide method (MTT), alkaline phosphatase kit and reverse transcription polymerase chain reaction reagent are also needed.

\section{Cell culture and experimental grouping:}

Healthy, two-month-old rats are selected and killed. After being disinfected with $75 \%$ medical alcohol, the knee joint of the hind limbs of the rats is severed on the super-clean table. Without opening the articular surface, the surrounding muscles are removed and they are put into the blank medium containing bi-antibodies. The articular cartilage surface is then separated. First, the synovial membrane on the cartilage surface is gently scraped, and the cartilage is cut off with a knife blade. The cartilage is placed in eppendorf (EP) tubes containing double-antibody blank medium and cut into $1 \mathrm{~mm}^{3}$-sized tissue pieces with ophthalmic scissors. In the centrifuge, $1000 \mathrm{r} / \mathrm{min}$ centrifugation is carried out and the supernatant and blank medium is discarded. $1.0 \mathrm{ml} 0.25 \%$ collagenase type II is added into EP tube and digested in a constant temperature water bath at $37^{\circ}$ with oscillation. Digestion is observed at intervals of $2 \mathrm{~h}$ until cartilage fragments are gradually digested. Cells are collected by centrifugation at $1000 \mathrm{r} / \mathrm{min}$. All collected cells are suspended in DMEM/F-12 complete culture medium (containing $15 \%$ fetal bovine serum,
$100 \mathrm{U} / \mathrm{ml}$ of penicillin and streptomycin respectively). The cells are inoculated in a $25 \mathrm{~cm}^{2}$-culture flask with the density of $2 \times 10^{5}$ and cultured in $5 \% \mathrm{CO}_{2}$, $37^{\circ}$ incubator. After $48 \mathrm{~h}$, the adherence of cells is observed and the liquid is changed. After that, the liquid is changed every $2 \mathrm{~d}$.

When chondrocyte confluence tablets are observed under inverted microscope (about $90 \%$ ), subculture is carried out. In the super clean table, the culture medium is poured out. Phosphate-buffered saline (PBS) is used to wash with three times, and $1 \mathrm{ml} 0.25 \%$ trypsin is added. Cells are observed under inverted microscope after $1 \mathrm{~min}$ in an incubator at $37^{\circ}$. Morphology begins to change, gradually becoming round, and individual cells begin to suspend. At this time, DMEM/F-12 complete medium is quickly added to terminate trypsinase digestion. The cells are then repeatedly blown to suspend and disperse, and placed in a centrifugal tube for $3000 \mathrm{r} / \mathrm{min}$ for $6 \mathrm{~min}$. The liquid is poured out, a proper amount of complete medium is added, and cells are repeatedly blown and counted. MC3T3-E1 cells are inoculated into H-DMEM medium (containing $10 \%$ fetal bovine serum, $10 \mathrm{~mm} \beta$-glycerol phosphate, $50 \mathrm{mg} / \mathrm{ml} \mathrm{L}$-ascorbic acid) at $4 \times 10^{5}$ per $\mathrm{cm}^{2}$ density. It is incubated in $37^{\circ}, 5 \% \mathrm{CO}_{2}$ and saturated humidity incubator. Dexamethasone is known to have osteogenic differentiation activity. Therefore, in this study, it is not used as a standard medium supplement, but as a positive control to compare the effects of alendronate.

Every 3-4 d, the cells grow into a single layer and are digested and passaged with $0.25 \%$ trypsin. After passage, MC3T3-E1 cells are divided into five groups. The first group is blank control group without inducer, and is cultured conventionally. The second group is positive control group, and $10^{-8} \mathrm{M}$ dexamethasone is added. The third, fourth and fifth groups are experimental group, and $10^{-6} \mathrm{M}, 10^{-8} \mathrm{M}$ and $10^{-10} \mathrm{M}$ Allen phosphoric acid is added, respectively. After several days of culture, MTT, ALP activity and reverse transcription polymerase chain reaction (RT-PCR) are measured, as described below.

\section{MTT assay for cell proliferation:}

MTT method, also known as MTT colorimetry, is a method to detect cell survival and growth. The detection principle is that succinate dehydrogenase in mitochondria of living cells can reduce exogenous MTT to water-insoluble blue-purple crystalline Methamide (Formazan) and deposit in cells, while dead cells have no such function. Dimethyl sulfoxide (DMSO) can 
dissolve methylidene in cells. The light absorption value of DMSO at $490 \mathrm{~nm}$ wavelength can indirectly reflect the number of living cells. Within a certain cell number range, the amount of MTT crystallization is proportional to the number of cells.

MC3T3-E1 cells are digested into a single cell suspension and inoculated into 96-well culture plates with $2 \times 10^{3}$ per hole. The volume of each hole is $200 \mu 1$. After overnight incubation at $37^{\circ}, 10^{-8} \mathrm{M}$ dexamethasone, $10^{-6} \mathrm{M}, 10^{-8} \mathrm{M}$ and $10^{-10} \mathrm{M}$ Allen phosphoric acid are added to the medium respectively. On the $2 \mathrm{nd}, 3 \mathrm{rd}$ and 4 th $\mathrm{d}$ after continuous culture, 5 holes are taken from each group for detection. Methods: $20 \mu \mathrm{l}$ MTT solution $(5 \mathrm{mg} / \mathrm{ml})$ is added to each pore, and it is incubated at $37^{\circ}$ for $4 \mathrm{~h}$. The supernatant is absorbed and discarded. $150 \mu \mathrm{l}$ DMSO is added to each pore and it is oscillated for $10 \mathrm{~min}$. The wavelength of $490 \mathrm{~nm}$ is selected. The light absorption value of each pore is measured by ELISA and the results are recorded.

\section{ALP activity determination:}

ALP is a marker enzyme of mature osteoblasts. It is also a specific index for evaluating osteogenic activity and tissue differentiation. The activity of ALP is positively correlated with the differentiation of osteoblasts.

MC3T3-E1 cells are inoculated into 6-well culture plates with $1.5 \times 10^{5}$ per well. After overnight incubation, $10^{-8} \mathrm{M}$ dexamethasone, and $10^{-6} \mathrm{M}$, $10^{-8} \mathrm{M}$ and $10^{-10} \mathrm{M}$ Allen phosphoric acid are added to the medium respectively. On the $2 \mathrm{nd}$, 3rd and 4 th $\mathrm{d}$ after continuous culture, 5 holes are taken from each group for detection. Methods: $20 \mu 10.2 \%$ Triton X-100 is added to the culture medium, adherent cells are scraped off and cell suspension is collected in centrifugal tube. The suspension is agitated for $10 \mathrm{~min}$ at $40^{\circ}$, and the supernatant is collected after centrifugation for $10 \mathrm{~min}$ at $2500 \mathrm{Xg}$. It is planted in 96 well culture plate with 50 $\mu \mathrm{l} /$ hole. ALP kit is used for ELISA, optical density value is measured at $405 \mathrm{~nm}$ and ALP activity is calculated at different time.

\section{RT-PCR:}

Bone morphogenetic protein-2, OC and Co11.I are related genes of osteoblasts. They are important markers of differentiation and maturation of osteoblasts. They are also important substances involved in the formation, metabolism and regeneration of bone tissue. MC3T3-E1 cells are inoculated into 6-well culture plates with $1.5 \times 10^{5}$ per well. After overnight incubation, $10^{-8} \mathrm{M}$ dexamethasone, $10^{-6} \mathrm{M}, 10^{-8} \mathrm{M}$ and $10^{-10} \mathrm{M}$ Allen phosphoric acid are added to the medium respectively. The expression of BMP-2, OC and collagen I (Coll.I) is detected on the 4th $\mathrm{d}$ after continuous culture. Methods: The culture medium in the culture plate is carefully absorbed, the cells are lysed by Trizol, the lysate is extracted by trichloromethane, and the total RNA is precipitated by isopropanol, and dissolved in Diethyl Pyrocarbonate (DEPC) treated water. Random hexamer primers are added to reverse transcriptase for reverse transcription. The fragments of BMP-2, OC and Coll. I genes are amplified by polymerase chain reaction. Specific primers and reaction conditions are shown in Table 1. PCR products are analyzed by agarose gel electrophoresis and observed under ultraviolet light.

\section{Data analysis:}

All data are analyzed by SPSS11.0 software. The experimental data are expressed by the mean standard deviation, and are processed by one-way ANOVA and double-tailed t-test, with $\mathrm{p}<0.05$ as the test standard.

\section{RESULTS AND DISCUSSION}

The results show that Allen phosphoric acid can stimulate the proliferation of MC3T3-E1 cells, as

TABLE 1: RT-PCR PRIMER SEQUENCE AND REACTION CONDITIONS

\begin{tabular}{|c|c|c|c|}
\hline Gene & Sequence & Cycle condition & Base number \\
\hline \multirow{2}{*}{ Type I collagen } & $\begin{array}{c}\text { F: } \\
\text { AGCGCTGGTTTCGACTTCAGCTTCC }\end{array}$ & $\begin{array}{l}95^{\circ} 30 \mathrm{~s} \\
60^{\circ} 30 \mathrm{~s}\end{array}$ & \multirow[t]{2}{*}{466 bp } \\
\hline & R: CATCGGCAGGGTCGGAGCCCT & $\begin{array}{l}72^{\circ} 30 \mathrm{~s} \\
35 \text { cycle }\end{array}$ & \\
\hline \multirow{2}{*}{ BMP-2 } & $\begin{array}{c}\text { F: } \\
\text { TCATAAAACCTGCAACAGCCAACTCG }\end{array}$ & $\begin{array}{l}93^{\circ} 1 \mathrm{~min} \\
60^{\circ} 1.5 \mathrm{~min}\end{array}$ & \multirow[t]{2}{*}{671 bp } \\
\hline & R: GCTGTACTAGCGACACCCAC & $\begin{array}{l}72^{\circ} 30 \mathrm{~s} \\
35 \text { cycle }\end{array}$ & \\
\hline \multirow{2}{*}{ Osteocalcin } & F: GGCCAGGCAGGTGCGAAGC & $\begin{array}{l}95^{\circ} 30 \mathrm{~s} \\
65^{\circ} 30 \mathrm{~s}\end{array}$ & \multirow[t]{2}{*}{$271 \mathrm{bp}$} \\
\hline & R: GCCAGGCCAGCAGAGCGACAC & $\begin{array}{l}72^{\circ} 30 \mathrm{~s} \\
35 \text { cycle }\end{array}$ & \\
\hline
\end{tabular}


shown in Table 2 and fig. 1. After $48 \mathrm{~h}, 72 \mathrm{~h}$ and $96 \mathrm{~h}$, compared with the results of MC3T3-E1 cell division in blank group, the proliferation of MC3T3-E1 cells increases significantly. Especially at the concentration of $10^{-8} \mathrm{M}$ Allen phosphoric acid, the splitting effect is the greatest $(1.77 \pm 0.03 *, 1.89+0.02 *, 1.53 \pm 0.03 *)$. The proliferation peak appears $72 \mathrm{~h}$ after $10^{-8} \mathrm{M}$ Allen phosphoric acid treatment $(1.89 \pm 0.02 *)$, which is $28 \%$ higher than that of blank control group. After $96 \mathrm{~h}$, the proliferation of the experimental group slows down, and there is no significant difference compared with the blank control group.

In this experiment, ALP activity is increased in varying degrees at different concentrations of alendrophosphate in different time periods compared with the blank group, as shown in Table 3 and fig. 2. After $48 \mathrm{~h}$ and $72 \mathrm{~h}, 96 \mathrm{~h}$ compared with the blank group, ALP activity increases significantly in the three groups. Especially at $10^{-8} \mathrm{M}$ concentration of Allen phosphoric acid, the ALP activity reaches the maximum $\left(1.17 \pm 0.06^{*}\right)$, $1.29 \pm 0.05), 1.13 \pm 0.03)$. After that, ALP activity in the experimental group increases gradually. The proliferation peak appears $72 \mathrm{~h}$ after $10^{-8} \mathrm{M}$ Allen phosphoric acid treatment $(1.29 \pm 0.05) .96 \mathrm{~h}$ after treatment, the proliferation of the experimental group slows down. In $10^{-6} \mathrm{M}$ Allen phosphoric acid group,

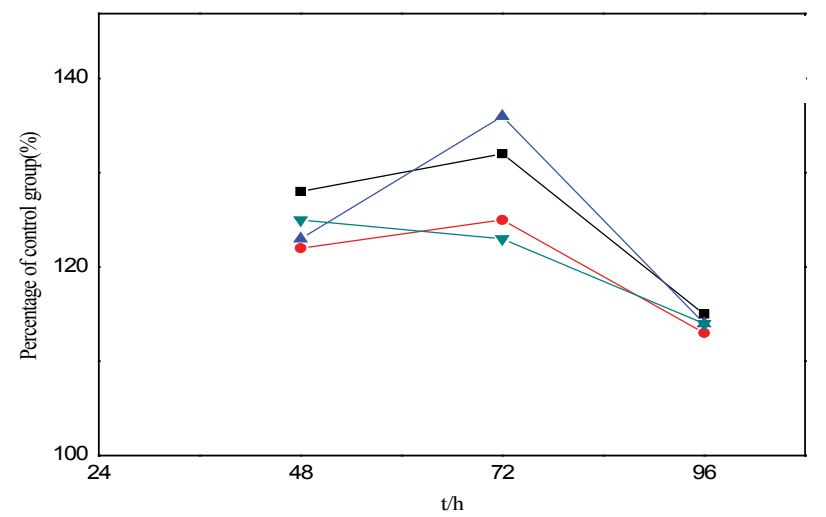

Fig. 1: Comparison of $m t t$ assay for cell proliferation $(p<0.05)$
ALP activity increases by $13 \%$ compared with the blank control group. In $10^{-8} \mathrm{M}$ Allen phosphoric acid group, ALP activity increases by $24 \%$ compared with the blank control group, which has a significant difference.

RT-PCR is used to detect the differentiation and maturation of MC3T3-E1 cells at the level of gene expression of ribonucleic acid (RNA). After $96 \mathrm{~h}$, BMP-2, OC and Coll.I are expressed in both control and experimental groups, as shown in fig. 3. The expression in the three groups of BMP-2, OC and Coll.I increases compared with the blank control group, and the expression of three target genes increases significantly in the $10^{-8} \mathrm{M}$ group. The samples are also analyzed until the $5^{\text {th }} \mathrm{d}$. The experiment show that BMP-2, OC and Coll.I can still be expressed in each group, but there is no significant difference among the groups.

In this study, the expression of MC3T3-E1 cells is detected by real-time quantitative PCR (RT-PCR). MTT (3- $(4,5)$ - dimethylthiahiazo (-z-yl) -3, 5-diphenytetrazoliumromide) is used to detect the proliferation of MC3T3-E1 cells and the effect on ALP activity, so as to explore its correlation. The results show that MC3T3-E1 cells have the greatest valueadded effect, the most significant gene expression and

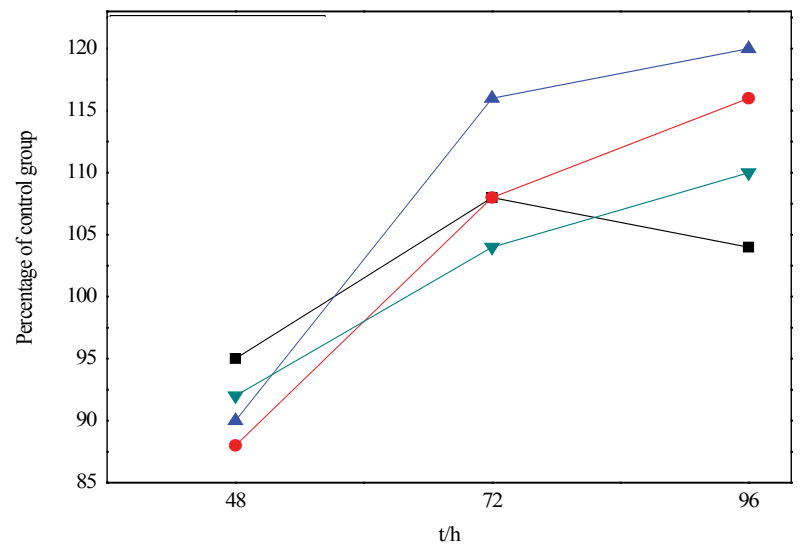

Fig. 2: Comparison of alp activity $(\mathbf{p}<\mathbf{0 . 0 5})$

TABLE 2: COMPARATIVE ANALYSIS OF CELL PROLIFERATION

\begin{tabular}{lcccc}
\hline & Dexamethasone & $10^{-6}$ M Allen phosphoric acid & $10^{-8}$ M Allen phosphoric acid & $10^{-10}$ M Allen phosphoric acid \\
\hline $48 \mathrm{~h}$ & $1.18 \pm 0.02^{*}$ & $1.52 \pm 0.01^{*}$ & $1.77 \pm 0.03^{*}$ & $1.03 \pm 0.05^{*}$ \\
$72 \mathrm{~h}$ & $1.63 \pm 0.05^{*}$ & $1.26 \pm 0.05^{*}$ & $1.89 \pm 0.02^{*}$ & $1.74 \pm 0.02^{*}$ \\
$96 \mathrm{~h}$ & $1.05 \pm 0.01^{*}$ & $1.01 \pm 0.06^{*}$ & $1.53 \pm 0.03^{*}$ & $1.34 \pm 0.01^{*}$ \\
\hline
\end{tabular}

TABLE 3: COMPARATIVE ANALYSIS OF ALP ACTIVITY

\begin{tabular}{lcccc}
\hline & Dexamethasone & $10^{-6}$ M Allen phosphoric acid & $10^{-8}$ M Allen phosphoric acid & $10^{-10}$ M Allen phosphoric acid \\
\hline $48 \mathrm{~h}$ & $0.78 \pm 0.12$ & $1.02 \pm 0.06^{*}$ & $1.17 \pm 0.06^{*}$ & $0.93 \pm 0.15^{*}$ \\
$72 \mathrm{~h}$ & $1.15 \pm 0.25$ & $1.21 \pm 0.05$ & $1.29 \pm 0.05$ & $1.04 \pm 0.12$ \\
$96 \mathrm{~h}$ & $1.05 \pm 0.02^{*}$ & $1.01 \pm 0.03^{*}$ & $1.13 \pm 0.03$ & $1.08 \pm 0.16^{*}$ \\
\hline 66 & & Indian Journal of Pharmaceutical Sciences & Special Issue 8, 2020
\end{tabular}




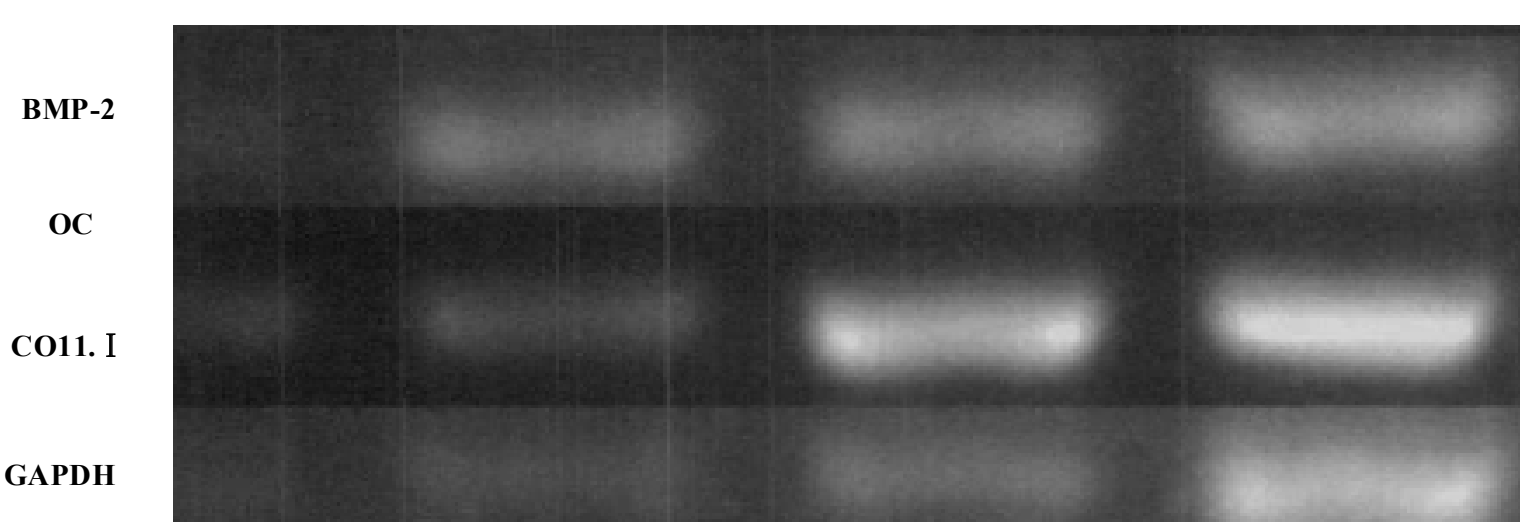

Fig. 3: Detection of BMP-2, OC, Type I collagen gene expression gapdh as housekeeping gene by RT-PCR

the highest ALP activity at the concentration of $10^{-8}$ M. The results are as expected. More accurate and quantifiable data for MC3T3-E1 cell proliferation are obtained through experiments.

In conclusion, it is known that diphosphate can alter the balance by regulating the concentration, affect the activity of osteoblasts, promote osteoblasts synthesis and division, and affect ALP activity and gene expression. However, there are still some deficiencies in this study. MC3T3-E1 cells have some defects, such as chromosome translocation and loss. MC3T3-E1 cells are not exactly the same as normal osteoblasts. The study of MC3T3-E1 cells cannot fully reflect the mechanism of osteoblasts.

\section{REFERENCES}

1. Yoo C K, Jeon J Y, Kim Y J. Cell attachment and proliferation of osteoblast-like MG63 cells on silk fibroin membrane for guided bone regeneration. Maxillofac Plast Reconstr Surg 2016;38(1):1-6.

2. Huang Q, Elkhooly T A, Liu X. Effects of hierarchical micro/nano-topographies on the morphology, proliferation and differentiation of osteoblast-like cells. Colloids Surf B Biointerfaces 2016;145:37-45.

3. Lim J, Shi Y, Karner C M. Dual function of Bmpr1a signaling in restricting preosteoblast proliferation and stimulating osteoblast activity in mouse. Dev 2016;143(2):339.

4. Han X G, Wang D W, Bi Z G. Regulatory effect of estrogen receptor- $\alpha$-mediated $\mathrm{Wnt} / \beta$-catenin signaling pathway on osteoblast proliferation. J Biol Regul Homeost Agents 2016;30(2):381.

5. Li Q, Li C, Xi S. The effects of photobiomodulation therapy on mouse pre-osteoblast cell line MC3T3-E1 proliferation and apoptosis via miR-503/Wnt3a pathway. Lasers Med Sci 2018:1-8.

6. Li Q, Chen Y, Dong S. Laser irradiation promotes the proliferation of mouse pre-osteoblast cell line MC3T3-E1 through hedgehog signaling pathway. Lasers Med Sci 2017;32(5):1-8.

7. Kawase M, Hayashi T, Asakura M. Proliferation of mouse fibroblast-like and osteoblast-like cells on pure titanium films manufactured by electron beam melting. Cell Biol Int 2016;40(10):1116-22.

8. Liu Y, Huang L, Hao B. Use of an Osteoblast Overload Damage Model to Probe the Effect of Icariin on the Proliferation, Differentiation and Mineralization of MC3T3-E1 Cells through the Wnt/ $\beta$-Catenin Signalling Pathway. Cell Physiol Biochem Int J Exp Cell Physiol Biochem Pharmacol 2017;41(4):1605.

9. Riddle R C, Clemens T L. Bone Cell Bioenergetics and Skeletal Energy Homeostasis. Physiol Rev, 2017; 97(2): 667-698.

10. Carnesecchi J, Vanacker J M. Estrogen-Related Receptors and the control of bone cell fate. Mol Cell Endocrinol 2016;432(1):37-43.

This is an open access article distributed under the terms of the Creative Commons Attribution-NonCommercial-ShareAlike 3.0 License, which allows others to remix, tweak, and build upon the work non-commercially, as long as the author is credited and the new creations are licensed under the identical terms

This article was originally published in a special issue, "Trends in Therapeutic Management of Various Clinical Conditions II" Indian J Pharm Sci 2021:83(2)Spl issue;63-67 